\title{
Hypochlorous Acid for Septic Abdominal Processes Using a Unique Negative Pressure Wound Therapy System: A Pilot Study
}

\author{
Marc R. Matthews ${ }^{1}$, Asia N. Quan ${ }^{2}$, Anushi R. Shah ${ }^{3}$, Carmen I. Tugulan ${ }^{3}$, Beshoy A. Nashed ${ }^{4}$ \\ Ross F. Goldberg' ${ }^{3}$, Paola G. Pieri ${ }^{3}$, Luis G. Fernandez ${ }^{5}$, Areta Kowal-Vern ${ }^{6}$, Kevin N. Foster ${ }^{1}$ \\ ${ }^{1}$ The Arizona Burn Center, Department of Surgery, Maricopa Integrated Health Systems, Phoenix, AZ, USA \\ ${ }^{2}$ Burn/Trauma Critical Care, Department of Inpatient Pharmacy, Maricopa Integrated Health Systems, Phoenix, AZ, USA \\ ${ }^{3}$ Department of Surgery, Maricopa Integrated Health Systems, Phoenix, AZ, USA \\ ${ }^{4}$ Department of Surgery, Mountain Vista Medical Center, Phoenix, AZ, USA \\ ${ }^{5}$ Division of Trauma Surgery/Surgical Critical Care, Trauma Surgical Critical Care Unit, Christus Trinity Mother Frances Health \\ System, Tyler, TX, USA \\ ${ }^{6}$ Department of Research, The Arizona Burn Center, Maricopa Integrated Health Systems, Phoenix, AZ, USA \\ Email: *marc_matthews@dmgaz.org
}

How to cite this paper: Matthews, M.R., Quan, A.N., Shah, A.R., Tugulan, C.I., Nashed, B.A., Goldberg, R.F., Pieri, P.G., Fernandez, L.G., Kowal-Vern, A. and Foster, K.N. (2018) Hypochlorous Acid for Septic Abdominal Processes Using a Unique Negative Pressure Wound Therapy System: A Pilot Study. Surgical Science, 9, 412-421.

https://doi.org/10.4236/ss.2018.911048

Received: September 25, 2018

Accepted: November 23, 2018

Published: November 26, 2018

Copyright $\odot 2018$ by authors and Scientific Research Publishing Inc. This work is licensed under the Creative Commons Attribution International License (CC BY 4.0).

http://creativecommons.org/licenses/by/4.0/ (c) (i) Open Access

\begin{abstract}
Background: Septic open abdomens occur in trauma, burn and surgery. Currently, multiple concentrations of hypochlorous acid solutions have effectively decreased the microbiotic burden in wounds. We hypothesized that Vashe $^{\circledR}$, a neutral hypochlorous acid solution (V-HOCL), would be safe as an intraperitoneal irrigation or washout disinfectant for septic open abdomens utilizing negative pressure wound therapy. Methods: This is a retrospective observational review of patients who required delayed abdominal closures after exploratory laparotomies. Group A $(\mathrm{n}=8)$ had cyclical V-HOCL irrigation to their open abdomens combining Abthera ${ }^{\mathrm{TM}}$ and V.A.C. Dressing System for negative pressure wound therapy with irrigation (NPWT-i) and Group B $(n=9)$ had intra-abdominal V-HOCL washouts. Results: Fifty percent of both groups had either septic or hemorrhagic shock on admission. Compared to Group B, Group A patients were older (median 50 vs 37 years), and had a median hospitalization of 28 vs 8 days, 4 times as many operations, more acute renal failure and co-morbidities. No statistically significant differences were detected between the two treatment methods with the V-HOCL delivery and removal. Conclusion: There were no episodes of electrolyte imbalance, hypotension, hypertension, anaphylaxis, hemorrhage, visceral injury or systemic toxicity. V-HOCL with/without NPWT-i irrigation was a safe modality and tolerated well in this study.
\end{abstract}




\section{Keywords}

Abthera $^{\mathrm{TM}}$, Hypochlorous Acid, Negative Pressure Wound

Therapy-Irrigation (NPWT-i), Septic Abdomen, Temporary Abdominal

Closure (TAC), V.A.C. VeraFlo ${ }^{\mathrm{TM}}$, Vashe ${ }^{\circledR}$

\section{Introduction}

Temporary Abdominal Closure (TAC) has become standard surgical management of the open abdomen in the setting of septic shock, coagulopathy, and damage control laparotomy. Negative pressure wound therapy (NPWT) evacuates intraabdominal fluid and purulent drainage during resuscitative measures and protects the exposed viscera for critically ill patients with open abdomens [1] [2] [3] [4]. New uses for NPWT include irrigation or washout TAC methods to reduce microbial contamination and promote healing [5].

In 1916, Fraser and Bates published successful treatment of appendiceal abscesses, viscus-perforating bullet wounds, and peritonitis with an antiseptic intra-abdominal washout using a $0.5 \%$ hypochlorous acid in normal saline (EUSOL) [6].

In their 6-month war experience, they were able to decontaminate wounds of gas gangrene, compound fractures, joints, skull fractures, chest, and abdominal surgery with EUSOL. Their report noted that hypochlorous acid as "Eusol" was a potent disinfectant in their experience, and helped their soldiers to survive. They performed rabbit experiments to confirm that a hypochlorous acid solution washout, (leaving some solution in situ upon closure), was without deleterious effect (such as adhesions) [6]. Hypochlorous (HOCL) acid is a beneficial wound cleanser. It reduces the prokaryotic organism burden to $10^{-2}$ power, while normal saline only reduces it to the $10^{-5}$ power [7]. One hundred three years later, it was used intra-abdominally again as an irrigant with NPWT-I documented in the literature as a case report [8]. This study aimed to evaluate the use of Vashe ${ }^{\circledR}$, (SteadMed. Inc., Fort Worth, TX) (V-HOCL) as a simple washout or irrigant, utilizing NPWT-i: Abthera ${ }^{\mathrm{TM}}$ (Acelity, Inc, San Antonio, TX) and V.A.C. Dressing System ${ }^{\mathrm{TM}}$ (Acelity, Inc, San Antonio, TX) in acutely ill patients with septic open abdomens. We hypothesized that the use of V-HOCL would be safe to use as an intra-abdominal washout and irrigation in the short and long term open septic abdomens. In addition, we hypothesize that V-HOCL is not hazardous to the peritoneum or serosal surfaces of the abdominal organs.

\section{Materials and Methods}

\subsection{Sample Population}

This was an observational pilot study (January 2017-January 2018) to determine the feasibility of utilizing V-HOCL as a washout or irrigant for septic open ab- 
domens. It entailed a retrospective chart review in patients treated with V-HOCL either as a washout for gunshot wounds, peritonitis, perforated viscus and damage control laparotomy resolution, or as an irrigant for patients who required longer term irrigation of their septic abdomens utilizing negative pressure wound therapy. The protocol encompassed trauma, burn and general surgery services. Hypochlorous acid as a disinfectant had not been reported in septic open abdomens since 1916. This was a preliminary trial use of hypochlorous acid in surgical patients with either open abdomens who required abdominal washouts during surgery or who required more intensive irrigation treatment with negative pressure wound therapy for a longer term. Inclusion criteria were determined by the operating surgeon based on acute illness factors in the operating room. There were 17 patients in two groups: Group A $(n=8)$ with $\mathrm{V}-\mathrm{HOCL}$ irrigation using two devices that have been denoted as off-label when used together: Abthera ${ }^{\mathrm{TM}}$ (Acelity, Inc, San Antonio, TX) and V.A.C. Dressing System ${ }^{\mathrm{TM}}$ (Acelity, Inc, San Antonio, TX), (patients requiring NPWT-i).Group $\mathrm{B}(\mathrm{n}=9)$ had an open abdomen with intra-abdominal V-HOCL washout and closure of the abdomen within 24 to 48 hours (mainly trauma patients). The Maricopa Integrated Health System Institutional Review Board approved this pilot study.

\subsection{Vashe ${ }^{\circledR}$ (V-HOCL) Wound Cleansing Solution [9] [10]}

Hypochlorous acid is usually formed as a final step in the oxidative burst pathway, killing pathogens within the neutrophil. It is a natural product biochemically created by the innate human immune system and well-tolerated in human tissues. Vashe ${ }^{\circledR}$ (V-HOCL) Wound Cleansing Solution (SteadMed. Inc., Fort Worth, TX) consists of normal saline with $0.033 \%$ hypochlorous acid added as a preservative. It has a neutral $\mathrm{pH}$ of 5.5 (range 4 - 6) compatible with that of the skin and is less toxic than chlorine or sodium hypochlorite. Peritoneal fluid $\mathrm{pH}$ is in the range of 7.5 - 8.0. Currently, V-HOCL is used to cleanse wounds, irrigate foreign materials, and disrupt biofilm. Since it is approved for external use only, V-HOCL was used off label in this study. In view of the literature report that a stronger hypochlorous acid disinfectant (EUSOL, 0.5\%) was used successfully without deleterious effect on the patients, the current weaker solution (0.033\%) was considered reasonable as an intraabdominal disinfectant for this study [6].

\subsection{ABTHERATM Therapy System [11]}

ABTHERA $^{\mathrm{TM}}$ Therapy System (Acelity ${ }^{\mathrm{TM}}$, San Antonio, TX) is designed to remove peritoneal fluid, reduce edema, minimize fascial retraction, loss of abdominal domain, and protect abdominal contents. It allows quick access for re-entry and does not require sutures for placement. This is the set up for NPWT, providing the covering and sponge layers over the open abdomen contents for this procedure (Figure 1). 


\section{Set-up for Abthera ${ }^{\mathrm{TM}}$-V.A.C.VeraFlo ${ }^{\mathrm{TM}}$ Therapy Irrigation of the Open Abdomen}
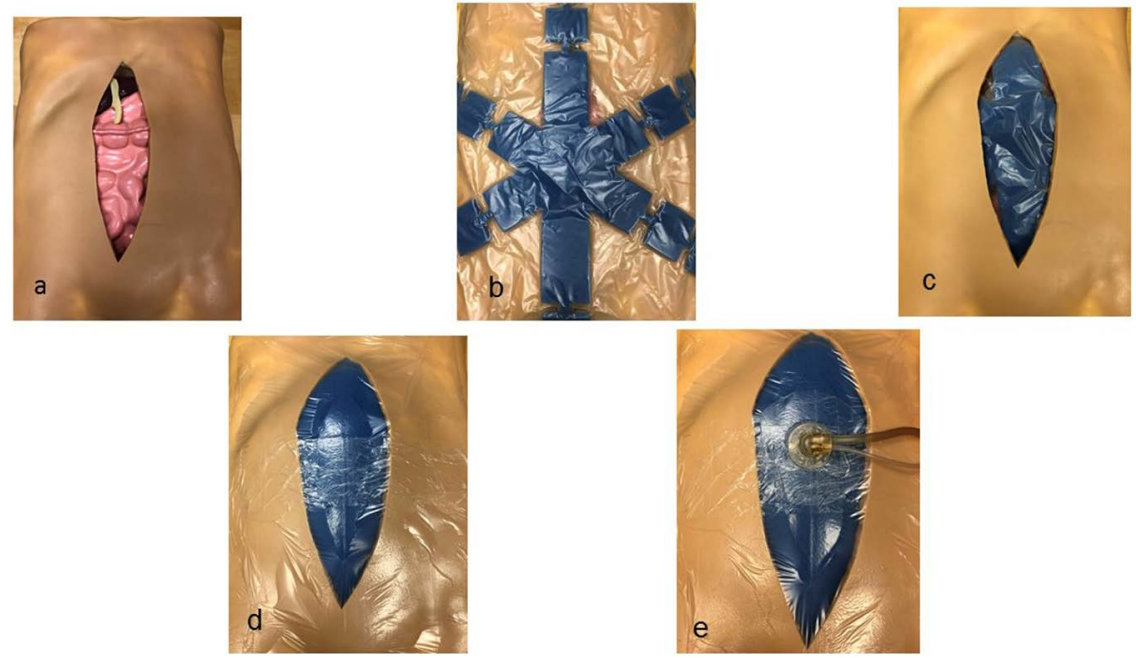

Figure 1. (a) Open abdomen post-washout without abdominal closure prior to Abthera ${ }^{\mathrm{TM}}$ placement; (b) Abthera ${ }^{\mathrm{TM}}$ device laid over the open abdomen to allow "cut to fit" for placement into the open abdomen; (c) Abthera ${ }^{\mathrm{TM}}$ placement into the open abdomen four quadrants; (d) Intraabdominal placement of blue overlay sponge covered with occlusive dressing; (e) Placement of the V.A.C. dressing suction (large diameter tube)/irrigation (smaller diameter tube) dual lumen port over the occlusive V.A.C. dressing for instillation of $\mathrm{V}-\mathrm{HOCl}$ and subsequent negative pressure wound therapy-irrigation (NPWT-i).

\subsection{V.A.C. Dressing System}

The V.A.C. Dressing System (Acelity ${ }^{\mathrm{TM}}$, San Antonio, TX) uses a single unit delivery and suction system that combines the benefits of VAC therapy with automated topical wound solution distribution and removal (Figure 2). It has two tubes bound together (Figure 1(e)). One lumen is for the volumetric instillation of irrigation fluid mostly on a wounded extremity or torso soft tissues, while the adjacent tubing, provides for the suction removal of that irrigation product. It is placed over the Abthera ${ }^{\mathrm{TM}}$ portion and through a hole in the VAC occlusive dressing which provides the connection for tube delivered inflow V-HOCL and outflow drainage (NPWT-i) as per the surgeon's programmed settings (Figure 2). Wolvos utilized this system in treating wounds with either a hypochlorous acid solution Microcyn ${ }^{\circledR}$ (Oculus Innovative Sciences, Petaluna, CA) or Dakin’s Solution ${ }^{\circledR}$ (Century Pharmaceuticals, Indianapolis, IN) [12].

\subsection{Procedure [8]}

Both groups had the immediate, standard abdominal washout and removal of succus entericus or stool with an initial one to three liters of normal saline. Group A proceeded with the Abthera ${ }^{\mathrm{TM}}$ device placement into each abdominal quadrant followed by an occlusive dressing and covered by the V.A.C. Dressing System $^{\mathrm{TM}}$. The combination of these two devices provided the best delivery of V-HOCL throughout the abdominal cavity with only one hole made in the occlusive dressing to accommodate the inflow and outflow tubing from the V.A.C. 


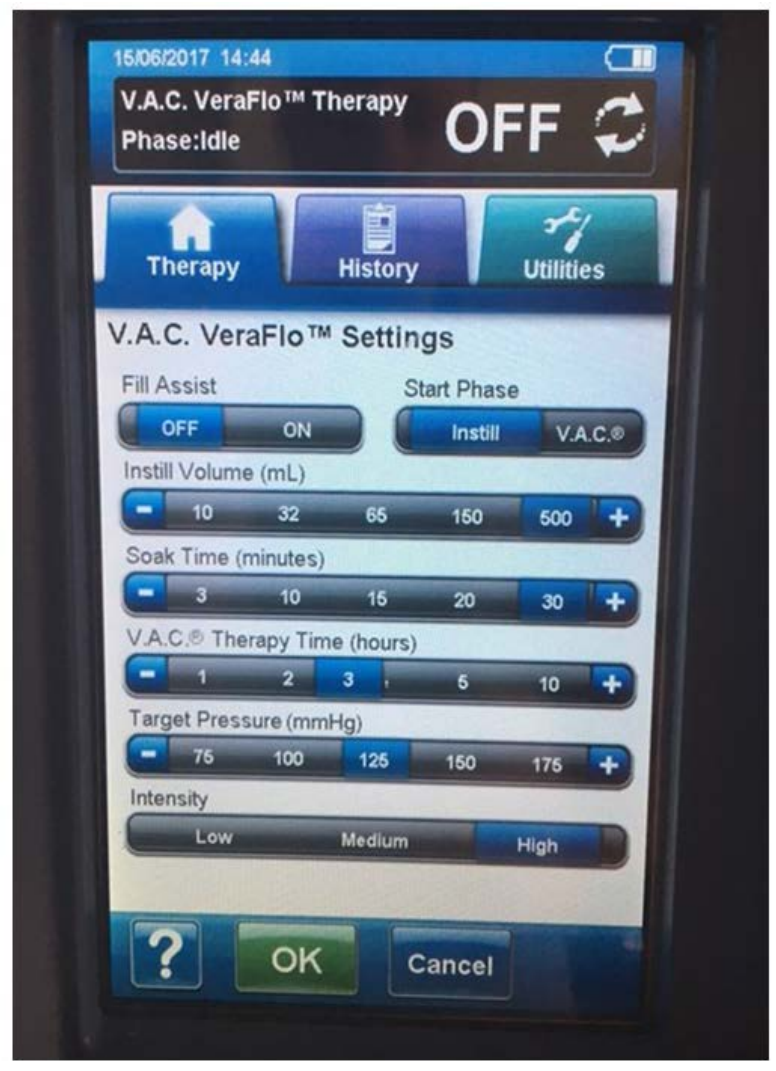

Figure 2. V.A.C. Veraflo ${ }^{\mathrm{TM}}$ Therapy settings for the intraabdominal irrigation of Vashe ${ }^{\circledR}$ (500 cc's over 30 minutes every three hours) alternating with continuous suction at 125 $\mathrm{mmHg}$.

Dressing System ${ }^{\mathrm{TM}}$. This utilization of the two products together permitted the irrigation of the open toxic abdomen repeatedly as if going to the operating room every three hours for irrigation.

Each irrigation consisted of $500 \mathrm{ml}$ of V-HOCL every 3 hours with a dwell time of 30 minutes for the instillation period. Group B had an intraabdominal $\mathrm{V}-\mathrm{HOCL}$ washout at the end of the operation, which remained in the open abdomen for 15 to 30 seconds before suction removal and closure either immediately or within the next 24 to 48 hours.

\subsection{Statistical Analysis}

Statistical Analysis was performed utilizing Statistica ${ }^{\circledR}$ (StatSoft, Tulsa, OK) descriptive statistics with ANOVA-one way and chi-squared. Patient demographics included: sex, age, diagnosis, comorbidities, length of stay (LOS), systemic toxicities, anaphylaxis, pre and post treatment levels of $\mathrm{CBC}$, chloride, lactate, $\mathrm{pH}$, and bicarbonate; renal failure, anastomotic breakdown, adhesions, and mortality. A $p$ value of $<0.05$ was considered significant.

\section{Results}

Table 1 describes the demographic characteristics of Group A (NPWT-i compared 
Table 1. Demographic characteristics.

\begin{tabular}{ccccc}
\hline Parameters & $\#$ & Group A (NPWT-i) & $\#$ & Group B (Washout) \\
\hline Age (years) & 8 & $49.3 \pm 14.6(24-66,50)$ & 9 & $45.8 \pm 16.3(28-69,37)$ \\
M/F & 8 & M4/F4 & 9 & M6/F3 \\
LOS (days) & 8 & $27.1 \pm 19.0(3-60,28)$ & 9 & $14.0 \pm 16.4(3-56,8)$ \\
Mortality (\%) & 4 & $50.0 \%$ & 0 & 0 \\
Diagnosis & & & & \\
Perforated Viscus (\%) & 5 & $38.5 \%$ & 8 & $61.5 \%$ \\
$\star$ Other (\%) & 3 & $75.0 \%$ & 1 & $25.0 \%$ \\
$\wedge$ Shock (\%) & 4 & $50.0 \%$ & 4 & $50.0 \%$ \\
Renal Failure (\#) & 8 & $75 \%(6)$ & 9 & $11.1 \%(1)$ \\
CRRT (\#) & 8 & $62.5 \%(5)$ & 9 & 0 \\
\hline
\end{tabular}

Mean \pm sd, (Range, Median); M/F = Male/Female. ${ }^{\star}$ Toxic Epidermal Necrolysis, Thermal Injury, Necrotizing Fasciitis; ^Septic or Hemorrhagic; NPWT-i = Negative Pressure Wound Therapy-Irrigation.

to Group B (Washout). Both groups tolerated V-HOCL washout/irrigations. Fifty percent of both groups were in either septic or hemorrhagic shock on admission. Group A had more severely ill patients (burns, necrotizing fasciitis, acute renal injury) versus mainly perforated viscus in Group B (Washout). Compared to Group B patients, Group A were older (median 50 vs 37 years), had a median hospitalization of 28 vs 8 days, 4 times as many operations, an increased frequency of acute renal failure ( $75 \%$ vs $11 \%$ ), $63 \%$ required continuous renal replacement therapy, and an overall increase in co-morbidities. Diabetes, cardiac disease, COPD, renal failure, psychiatric disease, and heroin abuse were the most common co-morbidities. The patients tolerated the procedure well and did not undergo episodes of hypotension, hypertension, anaphylaxis, or systemic toxicity. There were four mortalities in Group A that were attributed to the initial diagnosis and not to the NPWT-i treatment, which was an incidental confounding factor regarding these deaths. Of significance, the two anastomotic breakdowns in Group A did not occur during the V-HOCL irrigations.

In Table 2, as expected, Group A had a longer irrigation exposure to V-HOCL with the intraabdominal NPWT-i, median 23 liters (range 7 to 47 liters), compared to Group B, median 3 liters (range 1 to 3 liters). Table 3 shows the laboratory values pre- and post-washouts and irrigations. There were no statistically significant differences between the two treatment methods with V-HOCL delivery and removal. In both groups, the white blood cell count was decreased post-treatment, and serum chloride levels were slightly increased but within normal limits. Comparing Group A with Group B, pre-treatment hemoglobin was significantly decreased, (median 9.8 vs $12.6 \mathrm{~g} / \mathrm{dl}$, p $<0.01$ ) as were the platelets, (median 166 vs 312 , p < 0.047). There were no statistically significant differences between the two groups in lactate, $\mathrm{pH}$, and $\mathrm{CO}_{2}$ or $\mathrm{HCO}_{3}$ pre- and post-washout and irrigation procedures. 
Table 2. Operative data.

\begin{tabular}{ccccc}
\hline Parameters & $\#$ & Group A (NPWT-i) & $\#$ & Group B (Washout) \\
\hline V-HOCL solution (Liters) & 8 & $22.5 \pm 12.5(7-47,23)$ & 7 & $2.5 \pm 0.77(1.0-3.0,3.0)$ \\
Difference in fluid used p $<0.01$ & & & & N/A \\
V-HOCL Tx Time (Days) & 8 & $4.9 \pm 3.1(1-11,5)$ & 0 & $2.2 \pm 2.0(1-7,1)$ \\
Operations (\#) & 8 & $5.4 \pm 5.7(2-19,4)$ & 9 & $7.7 \pm 7.4(2-16,5)$ \\
${ }^{*}$ Abdomen Open (Days) & 8 & $7.9 \pm 7.4(2-25,5)$ & 3 & 0 \\
Anastomosis (\#) & 8 & $22.2 \%(2)$ & 9 & 0 \\
Adhesions (\#) & 8 & $37.5 \%(3)$ & 9 & \\
\hline
\end{tabular}

Mean \pm sd, (range, Median); no hemodialysis or anaphylaxis; NPWT-I = Negative pressure wound therapy-irrigation; Tx Time $=$ Treatment Time; ${ }^{*}$ the other 6 patients had their abdomens closed within $24-48$ hours.

Table 3. Laboratory values before and after irrigation and washout.

\begin{tabular}{ccccc}
\hline Parameters & $\#$ & Group A (NPWT-i) & $\#$ & Group B (Washout) \\
\hline $\begin{array}{c}\text { Chloride PreOp } \\
{ }^{*} \mathrm{p}<0.01\end{array}$ & 8 & $107.8 \pm 3.6(103-112,108)$ & 9 & $102.3 \pm 5.2(93-109,104)$ \\
$\begin{array}{c}\text { Chloride PostOp } \\
\text { WBC PreOp }\end{array}$ & 8 & $109.1 \pm 3.9(102-113,110.5)$ & 9 & $107.3 \pm 4.1(103-114,107)$ \\
WBC PostOp & 8 & $14.1 \pm 10.7(5.2-38.8,11.7)$ & 9 & $17.1 \pm 7.0(5.0-26.8,17.1)$ \\
Hgb PreOp & 8 & $10.0 \pm 2.4(6.3-14.9,9.8)$ & 9 & $13.7 \pm 3.1(9.9-18.2,12.6)$ \\
$\quad{ }^{*}$ p $<0.01$ & & $10.7 \pm 1.5(8.5-13.7,10.5)$ & 9 & $12.0 \pm 2.0(9.3-16.1,12)$ \\
Hbg PostOp & 8 & $18.3-21.3,13.2)$ & 9 & $13.1 \pm 7.4(1.3 \pm 22.9,15.0)$ \\
$\begin{array}{l}\text { Hct PreOp } \\
{ }^{*} \text { p }<0.01\end{array}$ & 8 & $27.1 \pm 9.2(10.9-42.8,28.2)$ & 9 & $39.6 \pm 8.6(27.6-53.7,37.9)$ \\
Hct PostOp & 8 & $31.8 \pm 4.3(25.8-39.3,30.8)$ & 9 & $35.1 \pm 5.8(27.5-46.5,35.2)$ \\
$\quad \begin{array}{l}\text { Plt PreOp } \\
{ }^{*} \text { p }<0.047\end{array}$ & 8 & $182.9 \pm 113.3(51-403,166)$ & 9 & $331.6 \pm 155(189-687,312)$ \\
Plt Post Op & 8 & $182.5 \pm 91.1(68-361,181)$ & 9 & $247 \pm 38(203-207,243)$ \\
\hline
\end{tabular}

Mean \pm sd, (range, Median); NPWT-I = Negative pressure wound therapy-irrigation; PreOp = Before procedure; PostOp = After procedure; $\mathrm{Hgb}=$ Hemoglobin; $\mathrm{Hct}=$ Hematocrit Plt $=$ Platelets .

\section{Discussion}

In this retrospective observational pilot study, both short term and prolonged care with V-HOCL as an intraabdominal disinfectant for the open septic abdomen was safe and beneficial to use in the setting of trauma, burn and general surgery. In addition, V-HOCL was not hazardous to the peritoneum or serosal surfaces of the abdominal organs as a washout solution or irrigant with NPWT-i. This study confirmed the findings and recommendations of Fraser and Bates in 1916 for the use of HOCL acid in septic open abdomens [6]. There were no systemic toxicities noted or attributed to utilizing V-HOCL in a protocol requiring intermittent fluid irrigation and drainage for a period of days (Group A) or as an open abdomen surgical washout solution (Group B).

Except for documentation by Fraser and Bates [6] (over a century ago), and Matthews [8], we were unable to find the use of any HOCL acid solution as an 
irrigant or washout of the open septic abdomen in the literature. HOCL acid solutions have been reported mainly as disinfectants for wounds at a risk for healing [12] [13]. Currently, NPWT has been a major player in the healing of surgical wounds.

Besides Matthews et al., there have been 3 reported studies between 2012 and 2017 utilizing NPWT-i for wounds at risk for healing, or septic abdomens [8]. Gabriel et al. reported 2 cases of deep wounds which benefited from V.A.C. VeraFlo $^{\mathrm{TM}}$ Therapy with Prontosan ${ }^{\circledR}$ (B. Braun Medical, Inc. Bethlehem, PA) and another case with normal saline [14]. Brinkert et al. used NPWT-i with normal saline on 131 diabetic and orthopedic wounds successfully [15]. Sibaja et al. documented normal saline irrigation in 48 patients with septic open abdomens in a controlled fashion in trauma and general surgery patients using NPWT-i [16].

Limitations of this retrospective observational study were the small number of patients. Although there was a protocol for the use of V-HOCL with NPWT-i in Group A, Group B patients obtained standard abdominal washout procedures with V-HOCL at the discretion of the operating surgeon. Neither Group A nor B procedures provided information as to the distribution of the irrigant or washout into all abdominal quadrants. There was no protocol in place for a standardized collection of abdominal fluid or intraabdominal cultures at baseline, during treatment or post treatment. Ongoing studies in the medical center are using V-HOCL and assessing the microbiology of the peritoneal cavity before and after washout or irrigation with V-HOCL.

\section{Conclusion or Summary Statement}

This pilot study has shown that Vashe ${ }^{\circledR}$, a $0.033 \%$ hypochlorous acid in normal saline solution is safe as a standard surgical intra-abdominal washout or NPWT-i irrigant using the combination of the Abthera ${ }^{\mathrm{TM}}$ device and V.A.C. Dressing System ${ }^{\mathrm{TM}}$ for septic open abdomens. In patients requiring an exploratory laparotomy and possibly an open abdomen for continuous irrigation or a single washout of the abdomen, these interventions may provide a benefit to the patient with a septic open abdomen.

\section{Funding}

There was no funding for this Pilot Study.

\section{Conflicts of Interest}

Each of the above listed authors declare that there are no conflicts of interest related to this manuscript, except for Marc R. Matthews, MD, Luis G. Fernandez, MD, who are surgical consultants for both Acelity, Inc., and SteadMed Medical, LLC.

\section{References}

[1] Navsaria, P., Nicol, A., Hudson, D., Cockill, J. and Smith, J. (2013) Negative Pres- 
sure Wound Therapy Management of the "Open Abdomen" Following Trauma: A Prospective Study and Systematic Review. World Journal of Emergency Surgery, 8, 4. https://doi.org/10.1186/1749-7922-8-4

[2] Lima, R.V.K.S., Coltro, P.S. and Farina, J.A. (2017) Negative Pressure Therapy for the Treatment of Complex Wounds. Revista do Colégio Brasileiro de Cirurgiões, 44, 81-93. https://doi.org/10.1590/0100-69912017001001

[3] Roberts, D.J., Zygun, D.A., Grendar, J., et al. (2012) Negative-Pressure Wound Therapy for Critically Ill Adults with Open Abdominal Wounds: A Systematic Review. Journal of Trauma and Acute Care Surgery, 73, 629-639. https://doi.org/10.1097/TA.0b013e31825c130e

[4] Lessing, M.C., James, R.B. and Ingram, S.C. (2013) Comparison of the Effects of Different Negative Pressure Wound Therapy Modes-Continuous, Noncontinous and with Instillation-On Porcine Excisional Wounds. Eplasty, 13, e51.

[5] D’Hondt, M., D’Haeninck, A., Derye, L., et al. (2011) Can Vacuum-Assisted Closure and Instillation Therapy (VAC-Instill ${ }^{\oplus}$ Therapy) Play a Role in the Treatment of the Infected Open Abdomen? Techniques in Coloproctology, 15, 75-77.

https://doi.org/10.1007/s10151-010-0662-4

[6] Fraser, J. and Bates, H.J. (1916) The Surgical and Antiseptic Values of Hypochlorous Acid (EUSOL). Journal of the Royal Army Medical Corps, 27, 79-84.

[7] Hiebert, J.M. and Robson, M.C. (2016) The Immediate and Delayed Post-Debridement Effects on Tissue Bacterial Wound Counts of Hypochlorous Acid versus Saline Irrigation in Chronic Wounds. Eplasty. 16, e32.

[8] Matthews, M.R., Quan, A.N., Weir, A.S., Foster, K.N. and Caruso, D.M. (2018) Temporary Abdominal Closure Combined with an Irrigating System Utilizing Hypochlorous Acid Solution to Decrease Abdominal Mucopurulence. Eplasty, 18, e12.

[9] Couch, K.S., Miller, C., Cnossen, L.A., Richey, K.J. and Guinn, S.J. Non-Cytotoxic Wound Bed Preparation: Vashe Hypochlorous Acid Wound Cleansing Solution. Wound Source White Paper.

http://www.steadmed.com/wp-content/uploads/2016/11/Vashe-Wound-CleansingFinal-final.pdf

[10] Robson, M.C., Payne, W.G., Ko, F., et al. (2007) Hypochlorous Acid as a Potential Wound Care Agent: Part II, Stabilized Hypo-Chlorous Acid: Its Role in Decreasing Tissue Bacterial Bioburden and Overcoming the Inhibition of Infection on Wound Healing. Journal of Burns and Wounds, 6, 80-90.

[11] Roberts, D.J., Jenne, C.N., Ball, C.G., Tiruta, C., Lèger, C., et al. (2013) Efficacy and Safety of Active Negative Pressure Peritoneal Therapy for Reducing the Systemic Inflammatory Response after Damage Control Laparotomy (the Intra-Peritoneal Vacuum Trial): Study Protocol for Randomized Controlled Trial. Trials, 14, 141.

http://www.trialsjournal.com/content/14/1/141

https://doi.org/10.1186/1745-6215-14-141

[12] Wolvos, T. (2013) The Use of Negative Pressure Wound Therapy with an Automated, Volumetric Fluid Administration: An Advancement in Wound Care. Wounds, 25, 75-83.

[13] Strohal, R., Mittlböck, M. and Hämmerle, G. (2018) The Management of Critically Colonized and Locally Infected Leg Ulcers with an Acid-Oxidizing Solution: A Pilot Study. Advances in Skin \& Wound Care, 31, 163-171. https://doi.org/10.1097/01.ASW.0000530687.23867.bd

[14] Gabriel, A. (2012) Integrated Negative Pressure Wound Therapy System with Volumetric Automated Instillation in Wounds at Risk for Compromised Healing. In- 
ternational Wound Journal, 9, 25-31.

https://doi.org/10.1111/j.1742-481X.2012.01014.x

[15] Brinkert, D., Ali, M., Naud, M., et al. (2013) Negative Pressure Wound Therapy with Saline Instillation: 131 Patient Case Series. International Wound Journal, 10, 56-60. https://doi.org/10.1111/iwj.12176

[16] Sibaja, P., Sanchez, A., Villegas, G., et al. (2017) Management of the Open Abdomen Using Negative Pressure Wound Therapy with Instillation in Severe Abdominal Sepsis: A Review of 48 Cases in Hospital Mexico, Costa Rica. International Journal of Surgery Case Reports, 30, 26-30. https://doi.org/10.1016/j.ijscr.2016.11.024 